\title{
Selection of Agricultural Foods by Eastern Grey Squirrels (Sciurus carolinensis): Implications for a New Introduction in British Columbia
}

\author{
JiLlian M. McAllister ${ }^{1}$, VAlerie LaW ${ }^{1}$, and Karl W. Larsen ${ }^{1,2}$ \\ ${ }^{1}$ Natural Resource Science Department, Thompson Rivers University, 900 McGill Road, Kamloops, British Columbia V2C 0C8 \\ Canada \\ ${ }^{2}$ Corresponding author: klarsen@tru.ca
}

McAllister, Jillian M., Valerie Law, and Karl W. Larsen. 2016. Selection of agricultural foods by Eastern Grey Squirrels (Sciurus carolinensis): implications for a new introduction in British Columbia. Canadian Field-Naturalist 130(3): $202-206$.

The recent introduction of the Eastern Grey Squirrel (Sciurus carolinensis) into south-central British Columbia occurred within an important agricultural zone. As repercussions for the fruit-growing sector are currently unknown, we conducted trials with captive squirrels to understand the range of fruits consumed and their preferences. The squirrels consumed a portion of every food item offered, although the order in which the foods were used was inconsistent (with sharp contrasts between animals). Of the fruit types offered, apples appeared to be of greatest overall interest. However, seeds and nuts tended to be used first when presented in combination with fruit, suggesting opportunities to use these food types to deflect or remove Eastern Grey Squirrels from orchard crops. We caution that our results may not reflect the food items that free-ranging Eastern Grey Squirrels will target or disregard once densities in the introduced population become higher and the availability of food on a local scale begins to exert an effect.

Key Words: Eastern Grey Squirrel; Eastern Gray Squirrel; Sciurus carolinensis; diet; food trial; invasive species; agriculture

\section{Introduction}

The Eastern Grey Squirrel (Sciurus carolinensis) is indigenous to the eastern forests of Canada and the United States, but it has been introduced at numerous locations around the globe, including areas in North America considerably distant from its native range (Lowe et al. 2000). In Canada, introduced populations of these animals have existed for decades on the west coast and in cities of the prairie provinces. After their earliest introduction in Vancouver, British Columbia, in the early 1900 s, grey squirrels rapidly populated the area (Robinson and Cowan 1954). In the 1960s, a few Eastern Grey Squirrels on Vancouver Island escaped captivity and established another stable population (Guiguet 1975; Nagorsen 2005).

In 2006, a new point of introduction for the Eastern Grey Squirrel in interior British Columbia was verified, although anecdotal reports date back to at least 2004 (K. W. L., unpublished data). The species is now established in the Okanagan Valley, particularly in Kelowna $\left(49.88^{\circ} \mathrm{N}, 119.44^{\circ} \mathrm{W}\right)$. The source population is most likely from Vancouver, approximately $300 \mathrm{~km}$ away with mountainous terrain between, strongly suggesting that humans transported the founding individuals of this relatively new population. This recent introduction has raised environmental and economic concerns (ISCBC 2012), although, to date, control measures have not been entertained. Because the Okanagan is one of the major agricultural regions of western Canada (particularly for fruit and vineyards), the potential exists for Eastern Grey Squirrels to affect commercially valuable crops. However, there is scant scientific literature focusing on specific ecological or economic effects of the Eastern Grey Squirrel in British Columbia, other than those predicted by Bruemmer et al. (2000).

In its native habitat, the Eastern Grey Squirrel has a broad diet, including fruit, nuts, seeds, flowers, buds, bark, fungi, and insects, as well as bird eggs and nestlings (Moller 1983; Koprowski 1994; Shealer et al. 1999; Spritzer 2002; Gurnell et al. 2004). This wide array enables the squirrels to exploit a variety of habitats including forested, urban, and cultivated areas (Riege 1991; Goheen et al. 2003; Gonzales 2005). Despite claims that the Eastern Grey Squirrel does not have a significant impact on agriculture in its native habitat (Woods 1980), a number of reports describe their destruction of corn, wheat, and vegetable crops in the United States, in some cases leading to implementation of a bounty (Schorger 1949; Byrne 1979; Koprowski 1994). In North America, introduced Eastern Grey Squirrels have been shown to raid fruit crops and gardens in urban areas (Bruemmer et al. 2000; Salmon et al. 2005). In Europe, Eastern Grey Squirrels damage timber and fruit trees by stripping their bark (Kenward and Parish 1986; Bruemmer et al. 2000), a behaviour not yet documented in non-native populations in North America.

Fruits consumed by Eastern Grey Squirrels include apples, cherries, blueberries, wild grapes, plums, and apricots (Banfield 1974; Byrne 1979; Salmon et al. 2005). As apples, cherries, and commercial wine grapes are widely produced in the Okanagan (Statistics Cana-

A contribution towards the cost of this publication has been provided by the Thomas Manning Memorial Fund of the Ottawa Field-Naturalist's Club. 
da 2014), the potential exists for Eastern Grey Squirrels to become an agricultural pest in this region. To date, however, their preferences for various commercially grown fruits in this region have not been studied. The objective of our study was to present captive Eastern Grey Squirrels with a range of food items, focusing on fruit crops produced in the Okanagan, to document their preferences and the breadth of their selection.

\section{Methods}

In early June 2014, three Eastern Grey Squirrels (one male and two females) were captured in Kelowna, British Columbia using live traps (Model 201, Tomahawk Live Trap, Hazelhurst, Wisconsin, USA) and transferred to the British Columbia Wildlife Park in Kamloops for housing. Neutering procedures were performed at the park's veterinary clinic as a precaution against escape. Each animal was also tagged with a standard numeric small-mammal ear tag (Monel \#1, National Band \& Tag Company, Newport, USA) to permit individual identification. Three weeks of postsurgical recovery were allowed before testing.

The three animals were housed in separate but adjacent cages. Each cage consisted of an outdoor screened enclosure (about $2 \mathrm{~m} \times 2 \mathrm{~m} \times 3 \mathrm{~m}$ tall) containing logs, climbing poles, and nest boxes, connected via a small doorway $(20 \mathrm{~cm} \times 20 \mathrm{~cm})$ to an indoor screened feeding cage $(60 \mathrm{~cm} \times 30 \mathrm{~cm} \times 45 \mathrm{~cm}$ tall $)$ where food was provided. Motion-detecting wildlife cameras (Trophy model 119477, Overland Park, Kansas, USA) were positioned inside each feeding cage to record feeding activities and allow us to determine order of food preference. During periods between trials with different food combinations (minimum two days), the squirrels were maintained on a daily diet of half a cup of Laboratory Rodent Diet 5001 (LabDiet, St. Louis, Missouri, USA) and three peanuts. Fresh drinking water was always available. The small sample size $(n=3)$ was due in part to a desire to provide large, individual seminatural environments that enabled the squirrels to roam larger areas and feed at times of their own choosing.

Each squirrel was presented with 11 combinations of three foods, chosen from 11 items (Table 1), and each combination was presented to each squirrel in three replicate trials, conducted over three consecutive days (one trial/day), resulting in 99 trials over the course of the study (June to October 2014). Because fruit was the main type of food under consideration, the order in which these locally grown items were presented in the trials corresponded to their seasonal availability (e.g., strawberries and cherries were used in early trials, and wine grapes and apples were introduced toward the end of the growing season). Two non-fruit foods were also included in the trials (peanuts and a commercial bird seed mix - Nyjer ${ }^{\circledR}$ brand, Wild Bird Feeding Industry, West End, USA) to test choice between these highenergy items and fruit. Because of constraints on food
TABLE 1. Foods, codes, and combinations used to evaluate preferences of three Eastern Grey Squirrels (Sciurus carolinensis), between June and October 2014.

\begin{tabular}{lcc}
\hline \hline Food & Code & $\begin{array}{c}\text { Food } \\
\text { combinations }\end{array}$ \\
\hline Apple & AL & PN, BS, SB \\
Apricot & AP & PN, CH, AP \\
Bird seed & BS & PN, PC, AP \\
Cherry & CH & PN, CH, PC \\
Peach & PC & AP, CH, PC \\
Peanut & PN & PN, AL, PR \\
Pear & PR & BS, AL, PR \\
Red wine grape $\quad$ (Cabernet-Franc) & RG & BS, RG, WG \\
White wine grape (Riesling) & RI & AL, RG, WG \\
Strawberry & SB & PR, RG, WG \\
White wine grape & & \\
$\quad$ (Gewürztraminer) & WG & AL, RG, RI \\
\hline \hline
\end{tabular}

availability and scheduling, each food item used in the study was not included in an equal number of trials.

For each trial, $\sim 50 \mathrm{~g}( \pm 1 \mathrm{~g})$ of each food was presented in a row of small ceramic dishes so that each dish was $30 \mathrm{~cm}$ from the feeding cage entrance. The order of the foods was rotated from left to right every trial to minimize the effect of location on the order of selection. Fruit items were presented intact (e.g., strawberries) or cut into large pieces (e.g., peaches) to approximate the situation found in orchards. Access to the feeding cages and the food items was allowed for approximately $24 \mathrm{~h}$, after which the door was shut and the video recording retrieved from the cameras. The order in which the three food items were taken over the course of each trial (regardless of the amount taken) was used to designate first, second, and third food choice "preference." Because of an inherent delay in the camera's motion sensor, the subjects could enter the cage, grab a food item, and exit the cage before the camera recorded the full event. In most of these cases, order of selection was determined by visible changes in the amount of food in the dishes. Where this was not possible to discern, the trial was aborted and repeated the next day or the earliest possible date.

Realizing the limitations of our data, we simply report the proportion of trials where each food was chosen first, second, and third (using only the trials where that food item was present). In other words, we divided the number of times a food item was selected first (or second, or third) by the total number of trials in which that food item was offered. We also calculated the binomial probabilities for the frequencies at which the squirrels selected a particular food item first (i.e., $P=0.33$ [or one out of three food types], $q=0.66$ ), using only those trials in which the food item was included.

\section{Results}

All of the food items offered to the captive squirrels were eaten by at least one squirrel on at least one 
occasion. Feeding and/or plundering (i.e., food item removed but uncertain when it was consumed) of food from the feeding cages occurred primarily between 0400 and 0900 and between 1500 and 2100, with little interest shown between 2100 and 0400 .

No single food item emerged as clearly preferred by all three squirrels (Figure 1); bird seed and peanuts were chosen first relatively often, but even this pattern varied among squirrels. Apple was the fruit that, on average, was most frequently chosen first, although this was not consistent (chosen first in only $42 \%$ of all trials involving apple). An example of extreme variation occurred with cherries: Squirrel 2 selected cherries first in all of the trials in which this fruit was included, but Squirrel 1 did so in only two of nine trials (Figure 1; Table 2). The squirrels appeared relatively uninterest- ed in strawberries, wine grapes of all types, and apricots. Strawberries was the only food item never selected first in any trial, by any squirrel (and selected second in only one trial, by one squirrel); however, trials using this fruit were limited in number.

Similar patterns were reflected by the binomial probabilities calculated for the food choices demonstrated by the squirrels (Table 2$)$. Low probabilities $(P<0.10)$ suggesting a predilection for a food type were seen for particular squirrels for certain food items (e.g., Squirrel 1 and peanuts, Squirrel 2 and cherries), but not consistently for all three animals or any one food item. Peanuts came closest to this pattern, with low associated binomial probabilities, on average (0.07), but largely because two of the three squirrels chose peanuts first relatively often (14/15 and 9/15 trials). The bird

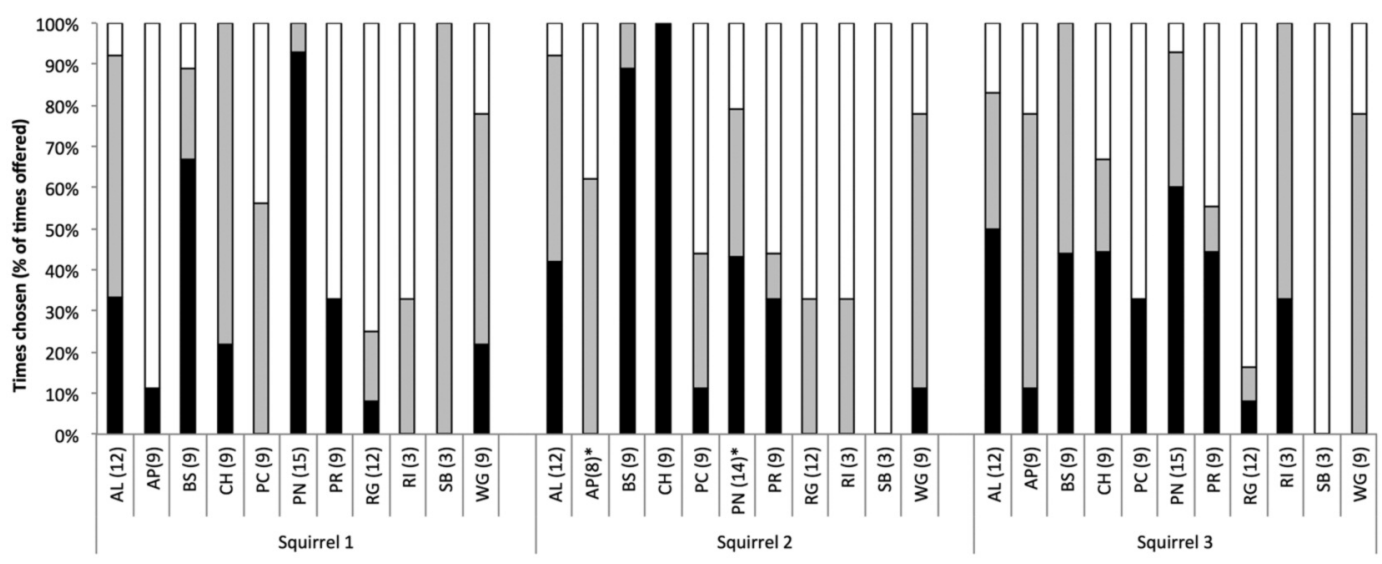

FIGURE 1. Food preferences of three Eastern Grey Squirrels (Sciurus carolinensis). Each food combination was presented to each squirrel in an equal number of trials (shown in brackets), except for two situations* where Squirrel 2 received one less trial. Note: $\mathrm{AL}=$ apple, $\mathrm{AP}=$ apricot, $\mathrm{BS}=$ bird seed, $\mathrm{CH}=$ cherry, $\mathrm{PC}=$ peach, $\mathrm{PN}=$ peanut, $\mathrm{PR}=$ pear, $\mathrm{RG}=$ red wine grape (Cabernet-Franc), $\mathrm{RI}=$ white wine grape (Riesling), $\mathrm{SB}=$ strawberry, $\mathrm{WG}=$ white wine grape (Gewürztraminer). Bar shading represents the proportion of trials involving each food type where it was chosen first (solid), second (grey) or third (white) among the choices available.

TABLE 2. Number of trials in which each food was selected first by an Eastern Grey Squirrel (Sciurus carolinensis) as a proportion of the number of times it was offered and the binomial probability associated with that outcome (Binom $P$ ). A minus sign in the last column indicates a situation in which all three animals chose the food first in fewer than half the trials. No reverse situations existed where a food was consistently selected more often than expected.

\begin{tabular}{lccccccc}
\hline \hline & Squirrel 1 & \multicolumn{5}{c}{ Squirrel 2 } & \multicolumn{5}{c}{ Squirrel 3 } & \\
Food & First/trials & Binom $P$ & First/trials & Binom $P$ & First/trials & Binom $P$ & Direction \\
\hline Apple & $4 / 12$ & 0.24 & $5 / 12$ & 0.18 & $6 / 12$ & 0.11 & - \\
Apricot & $1 / 9$ & 0.12 & $0 / 8$ & 0.03 & $1 / 9$ & 0.12 & - \\
Bird seed & $6 / 9$ & 0.03 & $8 / 9$ & $<0.01$ & $4 / 9$ & 0.20 & \\
Cherry & $2 / 9$ & 0.24 & $9 / 9$ & $<0.01$ & $4 / 9$ & 0.20 & - \\
Peach & $0 / 9$ & 0.03 & $1 / 9$ & 0.12 & $3 / 9$ & 0.27 & - \\
Peanut & $14 / 15$ & $<0.01$ & $6 / 14$ & 0.16 & $9 / 15$ & 0.02 & - \\
Pear & $3 / 9$ & 0.27 & $3 / 9$ & 0.27 & $4 / 9$ & 0.20 & - \\
Red grape (Cabernet-Franc) & $1 / 12$ & 0.05 & $0 / 12$ & $<0.01$ & $1 / 12$ & 0.05 & - \\
White grape (Reisling) & $0 / 3$ & 0.30 & $0 / 3$ & 0.30 & $1 / 3$ & 0.44 & - \\
Strawberry & $0 / 3$ & 0.30 & $0 / 3$ & 0.30 & $0 / 3$ & 0.30 & - \\
White grape (Gewürztraminer) & $2 / 9$ & 0.24 & $1 / 9$ & 0.12 & $0 / 9$ & 0.03 & - \\
\hline \hline
\end{tabular}


seed trials had a similar pattern, albeit a higher $P$ value generated by Squirrel 3. Conversely, consistent low probabilities associated with infrequent selection of food types were seen for red grapes. Low probabilities were not associated with the selection frequencies for other types of grapes, but this was likely because of the relatively scant number of trials involving these fruits.

\section{Discussion}

The three captive Eastern Grey Squirrels ate each of the 11 food items presented to them (in 11 different combinations). This wide selection was not surprising, given that the species is able to exploit diverse ecosystems (Riege 1991; Goheen et al. 2003; Gonzales 2005). Logistics and the seasonality of different fresh fruit crops prohibited rigorous cafeteria-style food trials where foods are tested equally against one another (Lobo et al. 2009; Plantan et al. 2012). Also in our case, we were attempting to understand how Eastern Grey Squirrels may target different foods at different times during the summer (i.e., apples will not likely coincide with peaches). Although these conditions prevent us from commenting strongly on the food preferences demonstrated by this species at this location, our results still indicate that squirrels may eat all of the regional fruits represented in our study, including wine grapes. Also, even our small sample size revealed strong differences in dietary preferences among animals for some foods such as cherries. Exposure to different food types by our squirrels before captivity may have contributed to this variation, but detecting such correlates would require more elaborate testing.

Our study did not include an exhaustive sampling of all potential foods (and combinations thereof) available in the Okanagan region. To attempt this would be unrealistic, given the broad omnivorous diet of this species and local availability of different foods likely has a large effect on the feeding behaviour of individual animals or subpopulations. Further, as the population of Eastern Grey Squirrels increases in the Okanagan, pockets of animals will exist in areas dominated by different crops, exposing them to a narrower choice and possibly resulting in considerably greater impacts on specific crops (Salmon et al. 2005). The Okanagan Valley has a semi-arid summer climate, and water requirements may drive Eastern Grey Squirrels to consume whatever fruit is available, a situation we did not attempt to simulate.

Thus, the infrequent use of certain foods by our study animals does not necessarily mean those foods would be avoided in the wild by free-ranging Eastern Grey Squirrels. This is particularly so given our small sample size and the marked variation in selection by individuals. However, our captive squirrels tended to choose peanuts and bird seed (high-energy food items) over fruit, suggesting that these items should prove successful in luring or trapping squirrels that are having an impact on fruit crops. This tactic may be less effective if the targeted crops are other nuts, as has already been seen in the Okanagan for walnut and hazelnut crops (N. Bothe, personal communication, 2014).

The loss of habitat of the Eastern Grey Squirrel in its native range (Goheen et al. 2003) may adversely affect the reproductive success of native nut-bearing trees (Goheen and Swihart 2003). Conversely, Eastern Grey Squirrels may have an negative impact on the regeneration of oaks (Fuchs et al. 2000; Steele et al. 2005), with possible implications in the fragmented stands of the endangered Garry Oak ecosystem in coastal British Columbia. However, in the Okanagan Valley, nut-bearing trees are primarily non-native and farmed; thus, Eastern Grey Squirrels foraging on these trees will have greater economic than ecological effects. The impact is likely to be more significant than that caused to date by the native Red Squirrel (Tamiasciurus hudsonicus), partly because the social system of the Eastern Grey Squirrel allows it to achieve higher urban densities. A close relative, the Eastern Fox Squirrel (Sciurus niger) was introduced in the Okanagan in the 1980s and has not been studied with regard to economic or ecological impacts, although agricultural damage is suspected by non-native populations in the United States (Frey et al. 2013).

This study provides a preliminary examination of food preferences of Eastern Grey Squirrels introduced into this region of Canada. Our work was done on a small number of captive animals, significantly limiting interpretation of the results. Still, it seems clear that the spread of the species throughout the agricultural region of the Okanagan Valley will likely not be impeded by the availability of food (at least during the fruit-growing season). Other landscape features, such as land-use patterns, natural barriers, and climate will likely affect extension of the species' range in this region. Further work, particularly in the field, is needed to address the potential and realized impacts of invasive tree squirrels in western Canada.

\section{Acknowledgements}

We thank the British Columbia Wildlife Park, specifically Adrienne Clay and Tara Geiger, for facilitating this study and Rebecca Tyson and the Guisachan Heritage Park for permitting live-trapping of Eastern Grey Squirrels on their properties. Thanks also to Harper's Trail Winery for providing wine grapes and David Sedgman, DVM, for performing surgeries. Naomi Bothe, Firefly Farm, is thanked for discussion about walnut and hazelnut crops of the Okanagan. Funding for this project came from the Invasive Species Council of British Columbia and a Thompson Rivers University undergraduate research scholarship to V. L. This work was conducted under protocol 100687 of the Thompson Rivers University Animal Care Committee and permit 78470-25 issued by the British Columbia Ministry of Forests, Lands and Natural Resource Operations. 


\section{Literature Cited}

Banfield, A. W. F. 1974. Mammals of Canada. University of Toronto Press, Toronto, Ontario, Canada.

Bruemmer, C., P. Lurz, K. Larsen, and J. Gurnell. 2000. Impacts and management of the alien eastern gray squirrel in Great Britain and Italy: lessons for British Columbia. Proceedings of the Conference on the Biology and Management of Species and Habitats at Risk, 15-19 February 1999. University College of the Cariboo, Kamloops, British Columbia, and Ministry of Environment, Lands and Parks, Victoria, British Columbia.

Byrne, S. 1979. The distribution and ecology of the nonnative tree squirrels Sciurus carolinensis and Sciurus niger in Northern California. Ph.D. thesis, University of California, Berkley, California, USA.

Frey, J. K., J. Iglesias, and K. Herman. 2013. Eastern Fox Squirrel (Sciurus niger): new threat to pecan orchards in far west Texas. Western North American Naturalist 73: 382-385.

Fuchs, M. A., P. G. Krannitz, and A. S. Harestad. 2000. Factors affecting emergence and first year survival of seedlings of Garry oaks (Quercus garryana) in British Columbia. Forest Ecology and Management 137: 209-219.

Goheen, J. R., and R. K. Swihart. 2003. Food-hoarding behaviour of gray squirrels and North American red squirrels in the central hardwoods region: implications for forest regeneration. Canadian Journal of Zoology 81: 1636-1639.

Goheen, J. R., R. K. Swihart, T. M. Gehring, and M. S. Miller. 2003. Forces structuring tree squirrel communities in landscapes fragmented by agriculture: species differences in perceptions of forest connectivity and carrying capacity. Oikos 102: 95-103.

Gonzales, E. K. 2005. The distribution and habitat selection of introduced Eastern Grey Squirrels, Sciurus carolinensis, in British Columbia. Canadian Field-Naturalist 119: 343350 .

Guiguet, C. J. 1975. An introduction of the Grey Squirrel, Sciurus carolinensis (Gmelin), to Vancouver Island, British Columbia. Syesis 8: 399 .

Gurnell, J., L. A. Wauters, P. W. W. Lurz, and G. Tosi. 2004. Alien species and interspecific competition: effects of introduced eastern grey squirrels on red squirrel population dynamics. Journal of Animal Ecology 73: 26-35.

ISCBC (Invasive Species Council of British Columbia). 2012. Invasive species strategy for British Columbia. Environment Canada, Ottawa, Ontario, Canada.

Kenward, R. E., and T. Parish. 1986. Bark stripping by gray squirrels. Journal of Zoology 210: 473-481.

Koprowski, J. L. 1994. Sciurus carolinensis. Mammalian Species 480: 1-9.

Lobo, N., M. Duong, and J. S. Millar. 2009. Conifer-seed preferences of small mammals. Canadian Journal of Zoology 87: 773-780.
Lowe, S., M. Browne, S. Boudjelas, and M. De Poorter. 2000. 100 of the world's worst invasive alien species: a selection from the Global Invasive Species Database. IUCN Invasive Species Group, Gland, Switzerland.

Moller, H. 1983. Foods and foraging behaviour of red (Sciurus vulgaris) and grey squirrels (Sciurus carolinensis). Mammal Review 13: 81-99.

Nagorsen, D. W. 2005. Lagomorphs and Rodents of British Columbia - Volume 4: The Mammals of British Columbia. Royal British Columbian Museum, Victoria, British Columbia, Canada.

Plantan, T., M. Howitt, A. Kotze, and M. Gaines. 2012. Feeding preferences of the red-billed oxpecker, Buphagus erythrorhynchus: a parasitic mutualist? African Journal of Ecology 51: 325-336.

Riege, D. A. 1991. Habitat specialization and social factors in distribution of red and gray squirrels. Journal of Mammalogy 72: $152-162$.

Robinson, D. J., and I. McT. Cowan. 1954. An introduced population of the gray squirrel (Sciurus carolinensis Gmelin) in British Columbia. Canadian Journal of Zoology 32: 261282.

Salmon, T. P., D. A. Whisson, and R. E. Marsh. 2005. Tree squirrels: integrated pest management for home gardeners and landscape professionals. Pest notes publication 74122 IPM Education and Publications, UC Statewide IPM Program, University of California, Davis, California, USA.

Schorger, A. W. 1949. Squirrels in early Wisconsin. Transactions of the Wisconsin Academy of Science, Arts, and Letters 39: 195-247.

Shealer, D. A., J. P. Snyder, V. C. Dreisbach, D. F. Sunderlin, and J. A. Novak. 1999. Foraging patterns of Eastern Gray Squirrels (Sciurus carolinensis) on goldenrod gall insects, a potentially important winter food resource. American Midland Naturalist 142: 102-109.

Spritzer, M. D. 2002. Diet, microhabitat use and seasonal activity patterns of Gray Squirrels (Sciurus carolinensis) in hammock and upland pine forest. American Midland Naturalist 148: 271-281.

Statistics Canada. 2014. Census of Agriculture, fruits, berries and nuts: North Okanagan, Central Okanagan, and Okanagan-Similkameen. Table 004-0214. Statistics Canada, Ottawa, Ontario, Canada.

Steele, M., L. A. Wauters, and K. W. Larsen. 2005. Selection, predation and dispersal of seeds by tree squirrels in temperate and boreal forests: are tree squirrels keystone granivores? Pages 205-222 in Seed Fate: Predation, Dispersal and Seedling Establishment. Edited by P. M. Forget, J. E. Lambert, P. E. Hulme, and S. B. Vander Wall. Centre for Agriculture and Bioscience International, Wallingford, United Kingdom.

Woods, Jr., S. E. 1980. The Squirrels of Canada. National Museums of Canada, Ottawa, Ontario, Canada.

Received 11 May 2015

Accepted 11 July 2016 